\title{
Knowledge and Practices on Fever and Home Management of a Febrile Child and Antipyretic Use: A Sri Lankan Experience
}

Hemal De Silva ( $\nabla$ hemal.des@gmail.com )

Ministry of health Sri Lanka https://orcid.org/0000-0003-2776-2622

Shreenika De Silva Weliange

University of Colombo Faculty of Medicine

Kumudu Weerasekera

Ministry of Health Sri Lanka

Research article

Keywords: Home management, Fever, Antipyretics

Posted Date: August 3rd, 2020

DOI: https://doi.org/10.21203/rs.3.rs-47934/v1

License: (1) This work is licensed under a Creative Commons Attribution 4.0 International License. Read Full License 


\section{Abstract}

Background: Fever, a common childhood experience requires correct home management and seeking medical advice at the correct time. The aim of this study was to assess the knowledge and practices of fever home management of a febrile child among the primary caregivers.

Methods: A descriptive cross-sectional study was carried out in four randomly selected wards at the Lady Ridgeway Hospital, in Sri Lanka. among 400 primary caregivers of children less than 12 years of age admitted with fever. A pre-tested, pre-coded, interviewer administered questionnaire was used to collect information. Measurement of temperature by the participants were also observed.

Results: Normal body temperature was correctly mentioned by $46.2 \%$ and mercury thermometer was identified as the best thermometer by $45.8 \%$. Nearly $3 / 4$ th stated that the dose of antipyretics should be calculated according to age and or body weight and their knowledge on dose calculations showed that in $70.9 \%$ the calculated dose was considered safe and effective. In practice, $54 \%$ of the study population had used a thermometer for detection and/or monitoring of fever. Paracetamol was used by $99 \%$ of the study population alone or in combination by to treat the febrile child at home before the hospital admission. Non-Steroidal AntiInflammatory Drugs were also used by $1.5 \%$. The dose of paracetamol given to the child was too low for $6.5 \%$ while it was too high for $24.5 \%$. Statistically significant associations $(p<0.05)$ were seen for correct technique of temperature measurement with higher education, higher family income and having a single child.

Conclusions: This study adds to the contemporary fever management literature, by assessing problem from another dimension, which was the knowledge and practices of the primary caregivers in providing home management to a febrile child. Several knowledge and practice gaps were identified, which could be corrected through the clinical and public healthcare system.

\section{Background}

In the backdrop of emerging of new infections and reemergence of certain infection in the world today, the identification and management of childhood fever becomes an important aspect to consider. Fever in childhood is a common acute presentation and is usually due to an infection or any other inflammatory process and may be the first manifestation of a severe infection such as a bacterial pneumonia, meningitis or viral encephalitis, although mostly, it is a self-limiting mild viral illness (1). In the tropical and subtropical countries fever due to infection may be the onset of a potentially fatal dengue haemorrhagic fever (DHF). In Sri Lanka too, where infections are a leading cause for childhood morbidity and mortality, fever is the most common reason for childhood hospital admissions (2). It is more of a worry, as the Dengue infection and the complicated states of it are prevalent in all parts of the island at present with several outbreaks since 2004 (3) .

The outcome of childhood fever is dependent on the primary caregivers (PCGs) knowledge, practices on management of a febrile child at home, and seeking appropriate medical advice at the correct time from a qualified medical practitioner. Studies that have assessed the knowledge of Medical Officers in the management of children with febrile illnesses both globally and locally have identified gaps $(4,5)$. It was seen from the study conducted in Sri Lanka that some of the practitioners prescribe Non-Steroidal Anti-Inflammatory Drugs (NSAIDs) (18) in the management of fever, which in the context of dengue endemicity can be harmful leading to 
complications such as bleeding in dengue syndrome $(6,7)$. Anecdotal evidence clearly shows that PCGs of children, do not have adequate and correct knowledge regarding childhood fever and therefore, do not practice correct procedures in the management of a febrile illness of their child at home (8). Correct knowledge and practices of PCGs can empower caregivers, increasing their confidence to provide optimum care to a febrile child and enable them to give optimal home-based practices and to seek proper and timely medical assistance $(9,10)$. Within this context we conducted this research to assess the knowledge on childhood fever and the knowledge and practices on home management of a febrile child among the primary caregivers of children less than 12 years of age.

\section{Methods}

Design and Setting: We carried out a hospital based descriptive cross- sectional study at the Lady Ridgeway Hospital for children, which is the premier teaching hospital for children in Sri Lanka with around 250 children admitted to its six general paediatric wards daily. The study was conducted during June and July 2017. The study protocol was reviewed by the Ethics Review Committees of the Sri Lanka College of Paediatricians and the Ethics review Committee of the Lady Ridgeway Hospital. The Ministry of Health Sri Lanka and the respective ward consultants gave permission to carry out the study.

Study participants, sample and data collection: Primary caregivers (PCG) of children under 12 years of age admitted with fever, who had been otherwise normal prior to this episode of fever were the study participants. A PCG was defined as the person providing care for the referenced child most of the time during the day. We excluded the PCGs of children with previously diagnosed chronic diseases such as thalassemia, nephrotic syndrome, chronic liver disease and who were having absolute and relative contraindications for administration of accepted antipyretics. A total of 384 PCGs were studied, from four of the six general paediatric wards which were randomly selected. Systematic sampling was used to select 100 PCGs from each ward using the ward admission register. Data collection was carried out by trained pre-intern medical officers. Participants were briefed about the study and informed written consent was taken using the information sheet and consent form in their own language. Questioning was carried out in a private place and in a confidential manner. Necessary care was taken to minimize any discomfort or delay to the caregiver, the child or to the ward staff.

Study instruments and variables: A pre-tested, pre-coded, validated interviewer administered questionnaire was used to collect information on socio-demographic characteristics of the PCG, information about the child, knowledge on childhood fever, knowledge and current practices on identification and measurement of fever at home, knowledge on causes and effects of childhood fever, knowledge and practices at home on management of a febrile child. This was developed by the research team and is given as an additional file. Effect of paracetamol dose was calculated based on age and weight of the child using the British National Formulary 2016-2017(11); and the dose was categorized as follows; under dose : <10mg / Kg body weight, correct dose: 10- $<15 \mathrm{mg} / \mathrm{Kg}$ body weight, acceptable dose: $15-18.75 \mathrm{mg} / \mathrm{Kg}$ body weight, over dose: $>18.75-25 \mathrm{mg} / \mathrm{Kg}$ body weight, and potentially toxic dose : $>25 \mathrm{mg} / \mathrm{Kg}$ body weight. The PCGs were asked to demonstrate the manner in which they measure temperature and was categorised as good and poor based on the observations.

Statistical analysis: Data were described as frequencies and percentages The percentage of responses to the questions has been calculated on the total of participants. The PCGs socio-demographic characteristics were assessed for association practice components on home management of febrile child using chi square statistic. 
'p' value $<0.05$ was taken as statistically significant. SPSS (Statistical Package for the Social Sciences) software version 21.0 was used for data analysis.

\section{Results}

\section{Study population and sample (Table 1)}

The age of the PCG ranged from 18 to 62 years with majority $(94.5 \%)$ being mothers. Around $3 / 4^{\text {th }}$ of the PCGs were full time home makers, had 2 or more children with $38 \%$ having upper secondary education. The PCGs stated that with regards to the reference child, $91.5 \%$ has had fever before the current episode, $7.5 \%$ and had a history of convulsions and $7.3 \%$ has had a family history of convulsions.

\section{Knowledge on Fever (Table 2)}

Normal body temperature value within the correct range (12) for axillary temperature was correctly mentioned by $46.2 \%$ of the PCGs. Although $52.8 \%$ knew that there is a change in normal body temperature during a day, only $3.5 \%$ knew the correct pattern of diurnal variation of normal body temperature. Majority of PCGs were able to mention the common causes for fever. Fits (convulsions) were identified as an effect of fever by $73.8 \%$ of PCGs. Only $1 / 3^{\text {rd }}$ mentioned dehydration as one of the effects.

\section{Temperature monitoring and other supportive measures (Table 3)}

Majority $(96.2 \%)$ mentioned that use of a thermometer is the best method to identify fever. However, only $54 \%$ of PCGs had used the thermometer during the current episode of fever. The axilla was mentioned as the best site for measurement of body temperature by $83.0 \%$, although practiced by only $58.7 \%$. Majority $(70.2 \%)$ knew that the thermometer should be kept at the site for more than 2 minutes or until the beep in case of a digital thermometer while $16 \%$ did not know the duration. However, in practice, only $51.2 \%$ said that they kept the thermometer for the correct duration while $40 \%$ did not use a thermometer at all and $8.8 \%$ did not keep the thermometer for an adequate length of time. Mercury thermometer was considered as the best thermometer by $45.8 \%$ while $34 \%$ mentioned digital thermometer as the best type of thermometer, while $20 \%$ said they did not know about thermometers. In practice $33.0 \%$ and $27.0 \%$ of the PCGs used the mercury and digital thermometers respectively. Tepid sponging with or without physical methods was perceived to be effective in reducing body temperature during a febrile episode by $97.0 \%$ while $91.7 \%$ practiced it during the current episode of fever. Oral hydration, rest, adequate feeding during illness was recognized as important by great majority. However, the proportion that practiced it during the current episode was less.

\section{Antipyretic use (Table 4)}

Majority of the PCGs (97.5\%) have used only paracetamol before seeking medical advice. A great majority $(97.7 \%)$ knew and practiced the appropriate measurement method for administration of the antipyretic dose. Nearly $3 / 4^{\text {th }}$ stated that the dose should be calculated according to age and or body weight. However, only $66.8 \%$ practiced it accordingly during this episode, while $31.5 \%$ stated that they asked others or gave a dose previously recommended by a doctor, friends or relatives. Nearly half knew the correct dosing interval of 4-6 hours while $49.3 \%$ thought it should be given less frequently. Figure 1 shows that nearly half of the PCGs have 
visited an allopathic general practitioner before admitting the child to the ward, while $7.5 \%$ did not seek any other medical assistance before admission.

The knowledge on dose calculations showed that the dose considered appropriate was safe and effective in $70.9 \%$, while it was unsafe for nearly one fifth of the study population being overdose for $14.5 \%$ and at potentially toxic level for $5.3 \%$. The calculated dose was ineffective therapeutically for $5.3 \%$ of the reference child. In practice, $24.5 \%$ of the PCGs had given paracetamol in an unsafe dosage, $18.5 \%$ getting an overdose and $6 \%$ a potentially toxic dose. An ineffective under dose was given to $6.5 \%$ of the children.

\section{Temperature measurement - observation (Table 5)}

Overall 58.8\% demonstrated the correct technique in temperature measurement. PCGs who were mothers, those who had a higher level of education, higher level of monthly family income and had only a single child demonstrated good technique which was statistically significant at $p<0.05$.

\section{Discussion}

This study assessed the knowledge of childhood fever and knowledge and practices on home management of a febrile child among 400 PCGs of children admitted with fever, together with their socio-demographic predictors. To the authors' knowledge, this is the first study assessing knowledge and practice of different aspects of home management namely temperature measurement, antipyretic use, physical measures to reduce temperature and supportive care in Sri Lanka, a developing country.

Results were analyzed considering guidelines and recommendations $(12,13)$. It revealed that less than half of the PCGs correctly identified the normal body temperature, while $52 \%$ knew of the temperature changes during the day. Blumenthal reported that $30 \%$ of the parents in the United Kingdom (UK) did not know the normal body temperature (14). A national survey conducted by Bertille et al in France revealed that $11 \%$ of parent's defined fever by a threshold lower than that recommended by the French drug agency and $66 \%$ of parents considered a lower cut off temperature for starting antipyretic drug treatment (15). The knowledge on the causes of fever was better than the knowledge on effects of fever. These findings highlighted that effective health education messages should be appropriately targeted based on evidence (15).

One major finding is that $40 \%$ had not used a thermometer for measuring the temperature although $96 \%$ have identified it as the best method. This might be due to lack of purchasing power of a digital thermometer, or simply due to the fact the PCGs think that touch method is also as effective. It was also seen that use of mercury (33\%) thermometer and digital (27\%) thermometers were comparable. In contrast a study in Iran showed that the most common method of temperature measurement was the forehead fever strip, the reason being that many mothers being unable to read a mercury thermometer (16). However, in India (Agrawal ) 75\% of the parents used the digital thermometer and the rest used the mercury thermometer (10).

The recommendations in the NICE guidelines is to use axillary or tympanic method although, mainly based on safety issues (13). The national guidelines do not recommend oral temperature measurement (12). In this study $58.7 \%$ used the axillary method which is lower than the rate reported in India which was $80 \%$. (10). Similarly, Polat et al in 2012 (17) revealed that the technique of measuring the body temperature by the caregivers in Turkey was not satisfactory as caregivers stated that they were not certain about the correct site (90\%) and the 
best type of thermometer (95\%) for body temperature measurement. Therefore, it is seen that although identifying temperature is seemed a simple technique there are gaps in correct practices in various parts of the world.

Fever reducing physical measurements techniques showed varying patterns and are comparable with Gunduz et al study in Turkey where around half of the mothers used fever-reducing techniques, such as the application of tepid cloths and cold baths, cologne and vinegar (18). Similarly in USA nearly $75 \%$ of the parents surveyed used sponging, although two thirds of them performed the technique incorrectly with alcohol, cold water or cold rags (19).

In the present study $99 \%$ of the study sample had given paracetamol to their children at home before visiting the medical practitioner. The use of antipyretics among children before accessing medical care with fever ranged (32.3\%-90.3\%) across the globe $(10,20,21,22,23)$. Antipyretics are available over the counter in Sri Lanka.

Considering the above it remains a doubt whether all these children needed paracetamol as the knowledge on normal body temperature values, fever temperature values, the practices on the method of identification of fever and the technique of measuring body temperature were inadequate among the PCGs as discussed earlier.

In this study, $6.5 \%$ of the PCGs had given a low dose of paracetamol while nearly $25 \%$ of them had given it in an unsafe manner (overdose or at potentially toxic level). Although only $1 \%$ of the study population thought that giving an overdose is not harmful, $4.7 \%$ had given a higher dose of paracetamol intentionally. Similar to this study, Chiappini et al showed that one third parents thought that a higher dose of an antipyretic is not dangerous (4). The carers may believe that a higher dose will bring the fever down faster, not realizing that it can harm the child. This may be due to the excessive worry and anxiety of the PCGs $(20,21)$. Fever management education should highlight the correct dose of antipyretic, method of calculating it correctly, administrating at the correct frequency as well as the possible harmful effects if given in an overdose. It is prudent that parents are properly educated regarding fever management, to ensure that correct antipyretics are safely administered.

This study revealed that $31.5 \%$ of the study population determined the dose of paracetamol according to the advice obtained from friends, relatives or a previous visit to a medical officer or by their own experience. Bertille et al also reported that the parents administered the paracetamol according to a previous prescription for the same child (15). Since the current age of the child as well as the weight have increased since obtaining the previous prescription, this method can lead to an under dosing of the antipyretic. The present study showed that $49.7 \%$ of the study population gave paracetamol $4-6$ hourly while another $48.2 \%$ gave at more than 6 hourly intervals, while only $0.8 \%$ gave at less than 4 hourly intervals in an unsafe manner. Bertille et al found that $24 \%$ of the parents who administered paracetamol and $14 \%$ who administered ibuprofen, complied with the recommendations (15).

Our investigation has potential limitations and interpretation of findings should be done accordingly. The findings of this study cannot be generalised to the entire population in Sri Lanka since the study population was the PCGs of children admitted to the premier government teaching hospital for children at a highly urbanised location. Rural areas were not well represented. The PCGs in this study who admitted their children to the government hospital may be different from those who admitted their children to certain private hospitals in Sri Lanka, where the level of comfort might be different. In Sri Lanka people coming to the government hospitals do not have to pay for the care they receive. Thus, some groups such as those with a high-income level, those in 
certain occupations and in high educational level may not be represented within this population due to difference in health seeking behaviour. Practices were assessed based on self-report and not on observations. Thus, the findings may be different to what was actually carried out at home.

\section{Conclusion}

While the primary caregivers have a general knowledge regarding fever and home management of a febrile child, they lack an in-depth knowledge to manage the situation with understanding the good care practices. The health care system has not been able to effectively educate parents and caregivers adequately about fever and management of a febrile child at home. findings highlight the variability in parents' practices and importance for health professionals to explore each parent's specific educational needs and target education interventions to reduce non-evidence based behaviours. Educational programs targeted to educate parents and other PCGs through the available health system may be an effective action to change the parents' understanding and management of fever.

\section{Abbreviations}

PCG: Principal care giver

NICE: National Institute for Health and Care Excellence

\section{Declarations}

\section{Ethics approval and consent to participate}

This study obtained ethical approval from the Ethics Review Committees of the Sri Lanka College of Paediatricians. All participants were informed about the study and provided written informed consent before the study was conducted. The written informed consent was approved by the ethics committee.

\section{Availability of data and materials:}

Datasets used and analyzed during this study are available from the corresponding author on reasonable request.

\section{Consent for publication}

All the data presented are in aggregate form and no individual data area presented. Therefore, not applicable.

\section{Competing interests}

The authors declare that they have no conflicts of interests.

Funding: None

Authors' contributions and consent for publication 
HD - made contribution to the design, planning the study, literature search, acquisition of data, analysis and interpretation of the results, drafting the manuscript and revising it critically and has given final approval of the version to be published.

SDW - contributed to the planning of the study, assisted in planning and carrying out data analysis, drawing conclusions and in revising it critically for important intellectual content the preparation of the research paper and has given final approval of the version to be published.

$\mathrm{KW}$ - contributed to the planning of the study, planning data analysis, drawing conclusions and in revising it critically for important intellectual content the preparation of the research paper and has given final approval of the version to be published.

\section{Acknowledgements}

Authors wish to thank the administrators of the hospital and the participants of the study for their support and participation.

\section{Authors' Details}

1 Department of Health, Ministry of Health, Nutrition and Indigenous Health, Sri Lanka

2. Department of Community Medicine, University of Colombo, Colombo, Sri Lanka

3 Department of Health, Ministry of Health, Nutrition and Indigenous Health, Sri Lanka

\section{References}

1. Holt J, White L, Wheaton G.R. et al.Management of fever in Australian children: a population-based sample survey. BMC Pediatrics.2020;20:16. Available at https://doi.org/10.1186/s12887-020-1911-y

2. Ministry of Health Sri Lanka. Anual Health Bulletin 2015. 2015. 19 p. Available at http://www.health.gov.Ik/moh_final/english/public/elfinder/files/publications/AHB/2017/AHB\%202015.pdf

3. Indoor mortality morbidity report 2014 Sri Lanka. Available at: http://www.health.gov.lk/moh_final/english/others.php?pid=110

4. Chiappini E, Parretti A, Becherucci P, et al. Parental and medical knowledge and management of fever in Italian pre-school children. BMC Pediatrics. 2012;12: 97. Available at https://doi.org/10.1186/1471-2431-1297

5. Kannangara KANS, Liyanage NSH, de Silva NSN, de Silva WSD, Kumbalatara KATG. Assessment of the knowledge of medical officers in the management of children presenting with febrile illnesses. Sri Lanka Journal of Child Health. 2015.44(2), pp.92-96. DOI: http://doi.org/10.4038/sljch.v44i2.7145

6. World Health Organization (WHO) Regional Office for South-East Asia. Dengue: guidelines for diagnosis, treatment, prevention, and control. Special Programme for Research and Training in Tropical Diseases [Internet]. 2009. Available at: http://whqlibdoc.who.int/publications/2009/9789241547871_eng.pdf

7. Epidemiology Unit Ministry of Health Sri Lanka. National Plan of Action for Prevention and Control of Dengue Fever. Epidemiology Unit Ministry of Health Sri Lanka 2009;39. 
8. Mahesh PKB, Arnold SM, Gunathunga MW, Lathaharan A, Ariyarathne AMN, Pannilahetti N, Mallawarachchi DSV. Home-based temperature measuring practices and their association with selected events of disease sequelae among children treated as dengue in a tertiary care setting in Sri Lanka. Journal of the College of Community Physicians of Sri Lanka. 2017;22(1), pp.30-38. DOI: http://doi.org/10.4038/jccpsl.v22i1.8084

9. De S, Tong A, Isaacs D, Craig JC. Parental perspectives on evaluation and management of fever in young infants: an interview study. Arch Dis Child. 2014;99(8):717-723. doi:10.1136/archdischild-2013-305736

10. AGRAWAL, Ravi Prakash et al. Perception of fever and management practices by parents of pediatric patients. International Journal of Research in Medical Sciences, [S.I.], v. 1, n. 4, p. 397-400, jan. 2017. ISSN 2320-6012. Available at: <https://www.msjonline.org/index.php/ijrms/article/view/2634>. Date accessed: 04 june 2020.

11. Pediatric Formulary Committee, British Medical Association, Royal Pharmaceutical Society of Great Britain, Royal College of Paediatrics and Child Health, Neonatal and Paediatric Pharmacists Group, England. Department of Health, et al. BNF for Children 2016-2017: September 2016-17. [Internet]. [cited 2020 Feb 7]. 1009 p. Available at: http://www.pharmpress.com/product/9780857113061/bnf-for-children-bnfc-20162017-ebook

12. Lokuarachchi NLPPS, editor. National Guidelines Management of a Febrile child. Ministry of Healthcare\& Nutrition Sri Lanka; 2007. 138-144 p

13. NICE Guideline. Fever in under 5s: assessment and initial management. Clinical guideline [Internet]. http://nice.org.uk/guidance/cg160. 2013. Available at: http://nice.org.uk/guidance/cg160

14. Blumenthal I. What parents think of fever. Family Practice. 1998;15(6):513-518. doi:10.1093/fampra/15.6.513

15. Bertille N, Fournier-Charrière E, Pons G, Chalumeau M. Managing fever in children: a national survey of parents' knowledge and practices in France. PLoS One. 2013;8(12):e83469. Published 2013 Dec 31. doi:10.1371/journal.pone.0083469

16. Ayatollahi J. Mothers' knowledge, perception and management of fever in children. Paediatr Today [Internet]. 2014;10(1):14-7. Available at:

http://www.paediatricstoday.com/index.php/pt/article/view/191/pdf

17. Polat M, Kara S, Tezer H, Tapısız A, Derinöz O, Dolgun A. A current analysis of caregivers' approaches to fever and antipyretic usage. J Infect Dev Ctries. 2014;8(3):365-371. Published 2014 Mar 13. doi:10.3855/jidc.3904

18. Gunduz S, Usak E, Koksal T, Canbal M. Why Fever Phobia Is Still Common?. Iranian Red Crescent medical journal. 2016; 18(8), e23827. https://doi.org/10.5812/ircmj.23827

19. Crocetti M, Moghbeli N, Serwint J. Fever phobia revisited: have parental misconceptions about fever changed in 20 years?. Pediatrics. 2001;107(6):1241-1246. doi:10.1542/peds.107.6.1241

20. Enarson MC, Ali S, Vandermeer B, Wright RB, Klassen TP, Spiers JA. Beliefs and expectations of Canadian parents who bring febrile children for medical care. Pediatrics. 2012;130(4):e905-e912. doi:10.1542/peds.2011-2140

21. khan A, Khan H, Said A B, Zeb A, Islam F. Knowledge, attitudes and practice of parents regarding Fever in children and its management at home. International Journal of Endorsing Health Science Research (IJEHSR) 2015; 3(3), 01-05. https://doi.org/10.29052/IJEHSR.v3.i3.2015.01-05 
22. Mason S, Thorp S, Burke D. Prehospital use of paracetamol among children attending the accident and emergency department. Emerg Med J. 2003;20(1):88-89. doi:10.1136/emj.20.1.88

23. de Bont EG, Francis NA, Dinant GJ, Cals JW. Parents' knowledge, attitudes, and practice in childhood fever: an internet-based survey. Br J Gen Pract. 2014;64(618):e10-e16. doi:10.3399/bjgp14X676401

\section{Tables}

Table 1 Characteristics of the PCG and the reference child $(\mathrm{N}=400)$ 


\begin{tabular}{|c|c|c|}
\hline Variable & No. & $\%$ \\
\hline \multicolumn{3}{|l|}{ Characteristics of PCG } \\
\hline \multicolumn{3}{|l|}{ Type of PCG } \\
\hline Mother & 378 & 94.5 \\
\hline Other & 22 & 5.5 \\
\hline \multicolumn{3}{|l|}{ District of residence } \\
\hline Colombo & 260 & 65.0 \\
\hline Gampaha & 117 & 29.2 \\
\hline Other & 23 & 5.8 \\
\hline \multicolumn{3}{|l|}{ Age category (in years\} } \\
\hline $18-35$ & 218 & 54.5 \\
\hline $36-62$ & 182 & 45.5 \\
\hline \multicolumn{3}{|l|}{ Ethnicity } \\
\hline Sinhalese & 247 & 61.8 \\
\hline Tamil & 70 & 17.4 \\
\hline Moors/Malay & 83 & 20.8 \\
\hline \multicolumn{3}{|l|}{ Highest educational level } \\
\hline G.C.E. O/L and below & 246 & 61.5 \\
\hline G.C.E. A/L and above & 154 & 38.5 \\
\hline \multicolumn{3}{|l|}{ Monthly family income(Rs) } \\
\hline$<50,000$ & 289 & 72.3 \\
\hline 50,000 or more & 111 & 27.7 \\
\hline \multicolumn{3}{|l|}{ Occupation type } \\
\hline Full time Part time or Self employed & 95 & 23.8 \\
\hline Full time engaged in household work & 305 & 76.3 \\
\hline \multicolumn{3}{|l|}{ Number of children } \\
\hline 1 & 101 & 25.3 \\
\hline $2-6$ & 299 & 74.8 \\
\hline \multicolumn{3}{|l|}{ Characteristics of the reference Child } \\
\hline \multicolumn{3}{|l|}{ Gender of the child } \\
\hline Male & 215 & 53.7 \\
\hline
\end{tabular}

Page 11/18 


\begin{tabular}{|c|c|c|}
\hline Female & 185 & 46.3 \\
\hline \multicolumn{3}{|l|}{ Age groups(years) } \\
\hline$<1$ & 49 & 12.3 \\
\hline$<5$ & 120 & 30.0 \\
\hline $5-<12$ & 231 & 57.7 \\
\hline Occurrence of fever before this episode & 366 & 91.5 \\
\hline Occurrence of past history of febrile convulsions & 30 & 7.5 \\
\hline Family history of febrile convulsions & 29 & 7.3 \\
\hline
\end{tabular}

Table 2 Knowledge on Fever: normal temperature and changes, causes and effects of fever

\begin{tabular}{|lll|}
\hline Indicator $(\mathbf{n}=400)$ & \multicolumn{2}{c|}{ Correctly identified } \\
\cline { 2 - 3 } & No. & $\%$ \\
\hline Normal body temperature values* & 185 & 46.2 \\
\hline Change in body temperature during the day & 211 & 52.8 \\
\hline Diurnal variation & 14 & 3.5 \\
\hline Cause for fever & & \\
\hline Common cold & 354 & 88.5 \\
\hline Pneumonia & 380 & 95.0 \\
\hline Brain fever & 317 & 79.3 \\
\hline Diarrhoea & 290 & 72.6 \\
\hline Dengue fever & 395 & 98.8 \\
\hline Effects of fever & & \\
\hline Discomfort & 258 & 64.5 \\
\hline Dehydration & 134 & 33.5 \\
\hline Fits & 295 & 73.8 \\
\hline
\end{tabular}

Table 3: Knowledge and practice of temperature measurement monitoring and other supportive measures to reduce temperature 


\begin{tabular}{|c|c|c|c|c|}
\hline \multirow{2}{*}{ Temperature measurement, monitoring and supportive methods } & \multicolumn{2}{|c|}{ Knowledge } & \multicolumn{2}{|c|}{ Practice } \\
\hline & No. & $\%$ & No. & $\%$ \\
\hline \multicolumn{5}{|l|}{ Method to identify fever } \\
\hline Thermometer & 385 & 96.2 & 216 & 54.0 \\
\hline Touch & 15 & 3.8 & 183 & 45.8 \\
\hline Other means & & & 01 & 0.2 \\
\hline \multicolumn{5}{|l|}{ Site of temperature measurement } \\
\hline Axilla & 332 & 83.0 & 235 & 58.7 \\
\hline Rectal & 04 & 1.0 & 00 & 00 \\
\hline Oral cavity & 42 & 10.5 & 05 & 1.3 \\
\hline Forehead & 02 & 0.5 & 00 & 00 \\
\hline Not used a thermometer & & & 160 & 40.0 \\
\hline \multicolumn{5}{|l|}{ Length of time to keep thermometer at the site } \\
\hline$<$ one minute & 12 & 3.0 & 08 & 2.0 \\
\hline $1-2$ minutes & 43 & 10.8 & 27 & 6.8 \\
\hline$>2$ minutes & 182 & 45.5 & 111 & 27.7 \\
\hline Until the beep & 99 & 24.7 & 94 & 23.5 \\
\hline Not used a thermometer & & & 160 & 40.0 \\
\hline Do not know & 64 & 16.0 & & \\
\hline \multicolumn{5}{|l|}{ Type of thermometer to use } \\
\hline Mercury & 183 & 45.8 & 132 & 33.0 \\
\hline Digital & 136 & 34.0 & 108 & 27.0 \\
\hline Ear & 01 & 0.2 & 00 & 00 \\
\hline Not used & & & 160 & 40.0 \\
\hline Do not know & 80 & 20.0 & & \\
\hline \multicolumn{5}{|l|}{ Physical measures to reduce temperature } \\
\hline Tepid sponging only & 07 & 1.8 & 89 & 22.2 \\
\hline Tepid sponging+ reduce clothes & 375 & 93.7 & 275 & 68.8 \\
\hline Tepid sponging+ reduce clothes+ wrapped clothes & 05 & 1.3 & 01 & 0.2 \\
\hline Tepid sponging + wrapped clothes & 01 & 0.2 & 02 & 0.5 \\
\hline Reduce clothes only & 07 & 1.8 & 23 & 5.8 \\
\hline
\end{tabular}




\begin{tabular}{|c|c|c|c|c|}
\hline None of the above & 03 & 0.7 & 10 & 2.5 \\
\hline Do not know & 02 & 0.5 & & \\
\hline Give more fluids to the child & 379 & 94.8 & 365 & 91.3 \\
\hline Rests the child & 374 & 93.6 & 358 & 89.5 \\
\hline Improve on feeding & 307 & 76.8 & 154 & 38.5 \\
\hline Keeps night vigil & 348 & 87.0 & 227 & 56.8 \\
\hline
\end{tabular}

Table 4: Knowledge and practice of antipyretic use 
Administration of antipyretics

Type of antipyretic

Paracetamol only

Paracetamol +NSAIDs

Paracetamol + NSAIDs+Ayurvedic tablet

Do not know

None

Method of administration of the correct dose

Specific dosimeter, other dosimeter, dropper or syringe

Other(household teaspoon)

Tablet size

Do not know

No antipyretic given

\section{Methods of determining the dose}

According to age and /or body weight

Ask others (previous dose recommended by a doctor, friends and relatives, experience or media)

Do not know

No antipyretic given

\section{Method of administration of the correct dose}

Specific dosimeter, other dosimeter, dropper or syringe

Other(household teaspoon)

Tablet size

Do not know

No antipyretic given

Interval between doses

$<4$ hourly

04

4-6 hourly

No.

339

48

02

11

148

06

243

294

99

07

Knowledge - best

measure

$\%$

No. \%

84.7

390

97.5

12.0

$06 \quad 1.5$

0.5

2.8

$04 \quad 1.0$

37.0

148

37.0

1.5

1.3

05

60.7

243

60.7

$03 \quad 0.8$

73.5

$267 \quad 66.8$

24.7

126

31.5

1.8

03

0.7

$04 \quad 1.0$

1.0

04

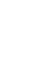




\begin{tabular}{|c|c|c|c|c|}
\hline$>6$ hourly & 197 & 49.3 & 193 & 48.2 \\
\hline Do not know & 08 & 2.0 & 01 & 0.3 \\
\hline No paracetamol given & & & 04 & 1.0 \\
\hline \multicolumn{5}{|l|}{ Dosing appropriateness } \\
\hline Ineffective - Under dose & 21 & 5.3 & 26 & 6.5 \\
\hline Safe and effective -Correct & 156 & 38.9 & 151 & 37.7 \\
\hline Safe and effective - Acceptable & 128 & 32.0 & 118 & 29.5 \\
\hline Unsafe -Overdose & 58 & 14.5 & 74 & 18.5 \\
\hline Unsafe - Potentially toxic & 21 & 5.3 & 24 & 6.0 \\
\hline Do not know & 16 & 4.0 & 03 & 0.8 \\
\hline No paracetamol given & & & 04 & 1.0 \\
\hline
\end{tabular}

Table 5: Technique of body temperature measurement and associated factors 


\begin{tabular}{|c|c|c|c|c|c|}
\hline \multirow{2}{*}{$\begin{array}{l}\text { Sociodemographic characteristics } \\
\text { Type of PCG }\end{array}$} & \multicolumn{2}{|c|}{$\begin{array}{l}\text { Good } \\
N=235,58.8 \%)\end{array}$} & \multicolumn{2}{|c|}{$\begin{array}{l}\text { Poor } \\
(\mathrm{N}=165,41.2 \%)\end{array}$} & \multirow[t]{2}{*}{$P$ value } \\
\hline & & & & & \\
\hline Mother & 227 & $60.1 \%$ & 151 & $39.9 \%$ & \multirow[t]{2}{*}{$p=0.028$} \\
\hline Other & 08 & $36.4 \%$ & 14 & $63.6 \%$ & \\
\hline \multicolumn{6}{|l|}{ Age groups (years) } \\
\hline $18-34$ & 134 & $61.5 \%$ & 84 & $38.5 \%$ & \multirow[b]{2}{*}{$p=0.227$} \\
\hline $35-62$ & 101 & $55.5 \%$ & 81 & $44.5 \%$ & \\
\hline \multicolumn{6}{|l|}{ Education } \\
\hline G.C.E. O/L and & 110 & $44.7 \%$ & 136 & $55.3 \%$ & \multirow[t]{2}{*}{$p=0.001$} \\
\hline G.C.E. A/L and above & 125 & $81.2 \%$ & 29 & $18.8 \%$ & \\
\hline \multicolumn{6}{|l|}{ Monthly family Income (Rs) } \\
\hline$<50,000$ & 148 & $51.2 \%$ & 141 & $48.8 \%$ & \multirow[t]{2}{*}{$p=0.001$} \\
\hline 50,000 or more & 87 & $78.4 \%$ & 24 & $21.6 \%$ & \\
\hline \multicolumn{6}{|l|}{ Occupation } \\
\hline Full time, Part time or Self-employed & 62 & $65.3 \%$ & 33 & $34.7 \%$ & \multirow[t]{2}{*}{$p=0.14$} \\
\hline Full time engaged in household work & 173 & $56.7 \%$ & 132 & $43.3 \%$ & \\
\hline \multicolumn{6}{|l|}{ No of children } \\
\hline One child & 71 & $70.3 \%$ & 30 & $29.7 \%$ & $p=0.006$ \\
\hline More than once child & 164 & $54.8 \%$ & 135 & $45.2 \%$ & \\
\hline
\end{tabular}

\section{Figures}




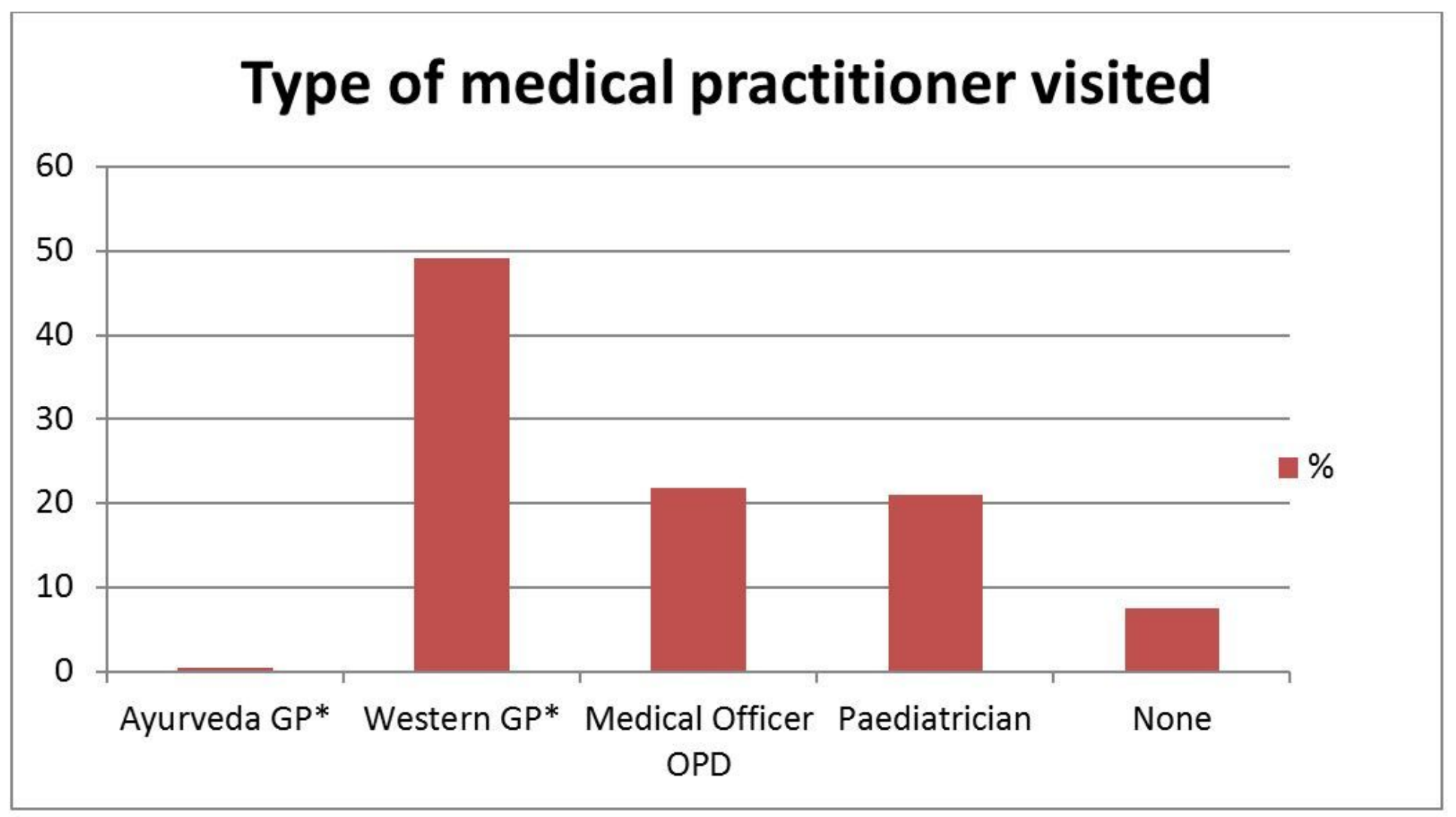

Figure 1

Type of medical practitioner visited.

\section{Supplementary Files}

This is a list of supplementary files associated with this preprint. Click to download.

- additionalfileEnglishquestionnaire.pdf 